\title{
Subvirtiendo la
}

democracia.

Viejas y nuevas claves

de lectura* /

Subverting

Democracy: Old and New

Reading Keys

* Recibido: 25 de enero de 2015. Aceptado: 3 de marzo de 2015.

Tla-Melaua, revista de Ciencias Sociales. Facultad de Derecho y Ciencias Sociales. Benemérita Universidad Autónoma de Puebla, México / IssN: 1870-6916 / Nueva Época, Año 9, No 39, octubre 2015/marzo 2016, pp. 92-107. 
La cuestión de la democracia aparece hoy como simple, pero en realidad es bastante compleja, ya que bajo la palabra democracia se ocultan muchas cosas diferentes. En este sentido, la palabra democracia se convirtió en un asunto político neurálgico. La complejidad de la cuestión de la democracia se pone en evidencia a través de todos los debates que hay actualmente sobre la noción de promoción de la democracia, lo cual está en el centro de la acción de la Unión Europea y, por supuesto, en el centro de la acción americana. Pero los europeos y los americanos no le dan la misma definición. Para simplificar, los americanos dan una definición que es estrictamente liberal e institucional, mientras que los europeos intentan defender una visión un poco más societal de la democracia.

El aporte de la reflexión sobre la historia y la acción de la democracia es poner de manifiesto que el desarrollo de la democracia no es simplemente el desarrollo de más democracia directa, sino de más reflexión, de más deliberación. Introducir la razón en el mundo público, eso es una definición de la democracia altamente subversiva.

\section{PALABRAS CLAVE}

Democracia, espacio público, sociedad civil, igualdad, libertad.
A B S T RACT

The topic of democracy appears today as simple, but in reality it is complex, because behind the word "democracy" there are several things that are hidden. In this sense, the word "democracy" became a neuralgic political issue. The complexity of the topic of democracy is evident through all discussions that currently exist around the idea of the development of democracy, which is located in the center of action of the European Union, and in the center of the American action. Nevertheless, Europeans and Americans do not share the same definition. To simplify, Americans have a definition that is strictly liberal and institutional, while Europeans try to defend a vision of democracy that is more societal.

The contribution of the reflection on history and the action of democracy is to demonstrate that the development of democracy is not merely the development of more direct democracy, but of more reflection and further deliberation. A highly subversive definition of democracy is to bring reasoning in the public opinion.

\section{KEYWORDS}

Democracy, Public Space, Civil Society, Equality, Freedom.

\footnotetext{
* Profesor investigador en la Facultad de Derecho y Ciencias Sociales de la Benemérita Universidad Autónoma de Puebla, México. (politicaparaciudadanos@gmail.com)
} 
Hace exactamente treinta años, el filósofo político italiano Norberto Bobbio publicó uno de sus libros más conocidos y citados, sobre todo en América Latina: El futuro de la democracia.${ }^{1}$ Probablemente ni el propio Bobbio imaginó el enorme impacto que esta obra alcanzaría en nuestra convulsionada región al poco tiempo de publicarse en su edición en español, el cual contrasta visiblemente con el que llegó a alcanzar en Europa, donde si bien Bobbio era un pensador respetado y reconocido, no era tan influyente como otros en los grandes debates intelectuales de los años ochenta del siglo pasado. De hecho, Bobbio prefería concentrar sus esfuerzos escribiendo sobre historia de las ideas y filosofía del derecho, más que participar puntualmente en los debates de su tiempo, pero cuando lo hacía sus opiniones nunca pasaban totalmente desapercibidas, sobre todo cuando escribía sobre los conflictos internacionales y el papel de los organismos multinacionales en la búsqueda casi siempre infructuosa de la paz y la distención, ${ }^{2}$ o cuando escribía sobre el socialismo y sus contradicciones. ${ }^{3}$

Ciertamente, El futuro de la democracia es un libro que analiza y disecciona magistralmente el saber acumulado durante la modernidad sobre la democracia, una obra que muestra el profundo conocimiento que sobre el tema tenía el pensador italiano. Sin embargo, no es en estricto sentido un libro que introduzca al debate una posición original sobre la democracia o una manera innovadora de entenderla. De ahí su escasa repercusión en la inteligencia europea de su tiempo. Pero esta ausencia era suplida con una dosis inconmensurable de claridad expositiva y eficacia argumentativa, virtudes que Bobbio supo cultivar como pocos a lo largo de su magisterio. Y es precisamente aquí donde reside el principal mérito de El futuro de la democracia, y que colocó a Bobbio en los cuernos de la luna en América Latina. Más precisamente, nunca nadie antes que Bobbio nos había explicado a los latinoamericanos de

\footnotetext{
${ }^{1}$ Bobbio N., Il futuro della democrazia, Turín, Giulio Einaudi Editore, 1984. La traducción al español apareció poco después: Bobbio N., El futuro de la democracia, México, FCE, 1986.

${ }^{2}$ Prueba de ello son sus libros: Bobbio, N., Il problema della guerra e le vie della pace, Boloña, Il Mulino, 1979 (trad. castellana: El problema de la guerra y las vías de la paz, Barcelona, Gedisa, 1982) o Bobbio, N., Il terzo assente. Saggi e discorsi sulla pace e sulla guerra, Turín, Giulio Einaudi Editore, 1989 (trad. castellana: El tercero ausente, Madrid, Cátedra, 2000).

${ }^{3}$ Bobbio N., Quale socialismo? Discussione di un'alternativa, Turín, Giulio Einaudi Editore, 1976 (trad. castellana: Qué socialismo. Discusión de una alternativa, Madrid, Plaza y Janés, 1977.
} 
manera tan clara y precisa qué es y qué no es la democracia, cuestión que fue altamente apreciada en esta parte del mundo, donde dicha noción había sido el centro de interpretaciones y disputas tan farragosas como insustanciales, en las que la democracia terminaba siendo todo y nada al mismo tiempo. ${ }^{4}$

Es evidente que el abuso indiscriminado de la palabra democracia por parte de partidos, actores políticos, activistas, gobernantes, etcétera, no es exclusivo de América Latina, pero aquí llegó a adquirir manifestaciones francamente delirantes, como la empleada por auténticos tiranos antediluvianos que se llenaban la boca de democracia para justificar sus brutalidades, o la de gobiernos supuestamente revolucionarios que al enarbolar la bandera de la justicia social se erigían como democráticos, aunque sus pueblos no gozaran de los derechos individuales más elementales. Además, la obra de Bobbio llegó en un momento crucial para la región, justo cuando empezaban a caer las dictaduras militares y se abría un horizonte democrático promisorio, motivado por las democratizaciones alcanzadas en el sur de Europa, pero sobre todo en España y Portugal, hacía apenas unos cuantos años atrás.

Por todo ello, si algo necesitaban nuestros países en esos años decisivos eran conceptos más que propaganda, era claridad más que ambigüedad, eran definiciones más que ficciones, eran razones más que ideología. De ahí que el libro de Bobbio cayó como anillo al dedo. Quién lo leyó entonces seguramente recordará su convincente distinción entre democracia formal y democracia sustantiva, o sea entre la democracia entendida como un conjunto de procedimientos que posibilitan la toma de decisiones colectivas por parte de un elevado número de ciudadanos, y la democracia entendida como un conjunto de principios y valores que marcan los fines vinculantes en una sociedad.

Asimismo, es muy probable que muchos recuerden la definición mínima de democracia aportada por Bobbio y que hasta la fecha sigue siendo enormemente clarificadora: conjunto de reglas que establece quién está autorizado a tomar las decisiones colectivas y con qué procedimientos, como el de facultar a un número elevado de ciudadanos el poder de tomar decisiones colectivas, el principio de mayoría, el respeto a los derechos individuales y la existencia de alternativas reales de entre las cuales los que deciden deberán elegir.

Pero sobre todo, ese lector acucioso muy seguramente recordará las muy sugerentes páginas de Bobbio dedicadas al tema de las promesas no cumplidas de la democracia o, parafraseando al pensador italiano, de las "promesas de marinero" de la democracia, que resultan de contrastar el ideal de la democracia (los valores que la definen) con la democracia realmente existente: a) lejos de garantizar que los individuos se afirmen como los verdaderos sujetos

\footnotetext{
${ }^{4}$ Otro autor que ensayó para México poco antes que Bobbio una definición mínima de la democracia, despojada de la propaganda política que prevalecía en esos años en América Latina, fue Enrique Krauze con su conocido ensayo "Por una democracia sin adjetivos", Vuelta, México, núm. 86, enero de 1984, pp. $4-13$.
} 
de la política, ésta ha sido asaltada por poderosos grupos de interés (sindicatos, partidos, asociaciones...); b) lejos de permitir la afirmación de un Estado representativo del todo social, el Estado se ha vuelto un mero mediador de los verdaderos intereses en disputa defendidos por poderosos grupos y corporaciones; c) lejos de hacer valer el ideal de un gobierno del pueblo, lo que realmente existe son oligarquías, aunque en un contexto más competitivo; d) lejos de ampliarse el sufragio a todos los ámbitos de la sociedad, éste se ha restringido al ámbito político electoral, debido a slas muchas resistencias e intereses que cruzan a las empresas o a las organizaciones de todo tipo; e) lejos de afirmarse la visibilidad del Estado por el principio del control de los ciudadanos sobre el poder, se ha afirmado un poder invisible (mafias, logias, etcétera) al lado del poder visible del Estado; y f) lejos de propiciar una ciudadanía más informada y participativa en los asuntos públicos, ha terminado por imponerse una creciente apatía y desinterés por parte de los ciudadanos.

En principio, conviene recordar, Bobbio atribuía las promesas incumplidas de la democracia a la creciente complejización de la sociedad, lo cual hizo estallar sin remedio los presupuestos previstos en el ideal de la democracia. Así, por ejemplo, se afirmaron gobiernos tecnócratas en todas partes dadas las exigencias de regular el mercado y la economía, lo que excluyó cada vez más a los ciudadanos de las decisiones colectivas por carecer estos del expertise necesario; simultáneamente, el Estado se burocratizó cada vez más por el impulso de las reivindicaciones sociales en la era de las políticas bienestaristas; y, finalmente, creció la ineficacia gubernamental por incapacidad para atender el creciente número de demandas sociales (crisis de gobernabilidad).

Como dijimos, han pasado exactamente treinta años desde que Bobbio expuso estas tesis, lo cual constituye un formidable pretexto para volver a ellas y evaluar su derrotero en las democracias realmente existentes del presente, sobre todo latinoamericanas, no tanto para resignificar la estatura intelectual de Bobbio a diez años de su muerte, pues no lo necesita, sino para repensar el tema de las promesas de la democracia en la actualidad. A primera vista, es muy probable que arribemos a la conclusión de que hoy la democracia acumula más pasivos que activos, o sea que cada vez son mayores y más visibles sus promesas no cumplidas que sus logros o conquistas. Sin embargo, bien miradas las cosas, quizá haya hoy más razones que hace treinta años para ser más optimistas que fatalistas. Veamos.

Ciertamente, aunque la democracia ha terminado por imponerse en casi todo el planeta como la única forma de gobierno legítima y preferible, incluso en países donde hace unos cuantos años parecía un derrotero inverosímil, hoy no podemos más que aceptar que las democracias realmente existentes están 
en crisis en todas partes. ${ }^{5}$ En mi opinión, se trata ante todo de una crisis de representación, pues los ciudadanos nos sentimos cada vez menos representados por nuestras autoridades, menos incluidos en los asuntos que nos atañen por parte de quienes nos representan y toman decisiones en nuestro nombre. Además, las democracias han tenido que lidiar con fenómenos de todo tipo que las debilitan sin remedio: incremento descomunal de los poderes fácticos o invisibles que terminan rebasando y suplantando al Estado en muchas de sus funciones sustantivas; supresión más o menos velada de algunos derechos elementales en nombre de la preservación de la seguridad nacional en tiempos de amenazas terroristas; ingobernabilidad creciente por incapacidad de los gobiernos para enfrentar la actual crisis económica del capitalismo; la afirmación global del sector financiero que somete a sus caprichos a todos los gobiernos del planeta; la incapacidad real de los gobiernos para frenar la creciente inequidad social y los muchos rezagos acumulados, entre otros muchos fenómenos.

En este sentido, es indudable que Bobbio acertó en prácticamente todo. $\mathrm{Su}$ diagnóstico sobre las promesas incumplidas de la democracia no podía ser más premonitorio. A la distancia de treinta años, hay muy poco que rebatirle. Y sin embargo, encuentro en Bobbio al menos un asunto que sí requiere un ajuste de cuentas, el que se refiere al papel que están llamados a representar los ciudadanos en el contexto de democracias crecientemente excluyentes y altamente deficitarias de representación política. Mi tesis aquí es que, contrariamente al fatalismo que subyacía en Bobbio al respecto, la crisis de representación de la democracia en lugar de alimentar la apatía de los ciudadanos o su inexorable desmovilización o exclusión política, ha propiciado múltiples formas de activación social en todas partes como expresión de un nuevo tipo de protagonismo de los ciudadanos en los asuntos públicos, desde la creación de organizaciones de todo tipo de la sociedad civil hasta movilizaciones masivas y acciones de resistencia cada vez más vigorosas e influyentes. Además, en los últimos años este creciente activismo social ha contado a su favor con las nuevas tecnologías de la comunicación, como las redes sociales, gracias a las cuales los ciudadanos en general han conquistado mayor visibilidad y centralidad. Pienso, por ejemplo, en los movimientos

\footnotetext{
${ }^{5} \mathrm{El}$ debate intelectual sobre la crisis de la democracia podría llenar bibliotecas enteras. En tiempos más recientes destacan las siguientes contribuciones: Rossanvallon P., La contre-démocratie. La politique à l'âge de la défiance, París, Seuil, 2006; Rossanvallon, P., La Légitimité démocratique. Impartialité, réflexivité, proximité, París, Le Seuil, 2008; Rossanvallon, P., La Société des égaux, París, Le Seuil, 2011 ; Runciman, D., The Confidence Trap. A History of Democracy in Crisis from World War I to the Present, Princeton, Princeton University Press, 2013. Habría que incluir también el muy comentado libro de Thomas Piketty, por cuanto sugiere que la democracia tendrá que sobrevivir en una era de crisis económica prolongada: Piketty, T., Le Capital au XXIème siècle, Paris, Seuil, 2013. Véase también el polémico ensayo de Meaney Thomas y Mounk Yascha, "What was Democracy?", The Nation, 13 de mayo de 2014. www.thenation.com/article/179851/ whatwas-democracy.
} 
sociales tanto de la Primavera árabe como de los indignados alrededor del mundo a partir del $2011 .{ }^{6}$ De hecho, como he sostenido en otras sedes, captar la novedad que la moderna cuestión social introduce para la democracia constituye en la actualidad un desafio ineludible para las ciencias sociales y el pensamiento político.?

Para entendernos, pongamos el caso de América Latina. Si en algún lugar se juega hoy la persistencia de la democracia en América Latina, pese a la crisis que padece y los enormes peligros que la amenazan y acechan, ese es precisamente el espacio de lo público-político (llámese la calle, la plaza, la escuela, la fábrica, la ONG, el barrio, el chat, el Twitter...), o sea el lugar donde los ciudadanos ratifican cotidianamente su voluntad de ser libres, el ámbito donde se producen los contenidos simbólicos cuya resonancia coloca cada vez más en vilo al poder instituido. Que las formas de articular y canalizar demandas sociales ya no pasen como antes, en la era del Estado benefactor, por el partido de masas o la central sindical o las grandes corporaciones, no significa que la sociedad haya renunciado a agregar intereses y a demandar soluciones, si acaso lo hace de manera distinta, desde la radical diferencia de los individuos, desde la pluralidad de sus intereses que ya no pueden ser homologados por agencias o agentes externos. En ese sentido, la deliberación pública y la cuestión social cobran un nuevo significado. La gestión de los conflictos pasa a ser inseparable de un esfuerzo colectivo para encontrar consensos sobre lo que es justo e injusto; y la política democrática se vuelve un camino común entre una maraña de preferencias individuales, escalas de valores y conceptos raramente coincidentes. En suma, la política democrática es un esfuerzo por hablar una misma lengua y ponerse de acuerdo sobre lo justo y lo injusto, cuestión que en América Latina no tendría sentido si no mediante el reconocimiento de una enorme deuda social dramática y lacerante.

Si la democracia se ha mantenido en la región, pese a sus muchas inconsistencias y graves problemas, es gracias precisamente - lo cual no deja de ser paradójico-, a la sociedad civil, a su creciente politización e involucramiento en los asuntos públicos y a una percepción muy clara de lo que significa vivir (y no vivir) en democracia, o sea a una cultura política cada vez más democrática. Es cierto que no se puede generalizar, que el grueso de nuestras poblaciones está tan ensimismado en resolver el día a día que lo menos que le interesa es la política, pero el dinamismo de aquella parte de la sociedad cada vez más consciente de su condición de ciudadano es tal que termina por "contaminarlo" todo, por apuntalar un andamiaje institucional y normativo

\footnotetext{
${ }^{6}$ Véase, por ejemplo, Cansino C., Schmidt S. y Nares G. (eds.), ¿Democratizando la democracia? De la Primavera árabe a los Indignados, México, Juan Pablos-BuAp, 2014.

${ }^{7}$ A los interesados en este tema los remito a los siguientes libros: Cansino C., La revuelta silenciosa. Democracia, espacio público y ciudadanía en América Latina, México, BUAP/CEPCom/Aled, 2011 y Cansino C., La nueva democracia en América, México, Juan Pablos, 2013.
} 
que, aunque maltrecho, nos da cobijo y resguardo. Es más, este nuevo protagonismo o activismo social ni siquiera se debe a un acto voluntario, o no sólo, sino sobre todo a una nueva realidad histórica que no dejaba más alternativa: el tránsito de un Estado social y proveedor a uno desobligado de dicha responsabilidad, el tránsito de la política de intereses colectivos a la de intereses individuales, el tránsito de sistemas cerrados a sistemas abiertos, de regímenes autoritarios donde se pisoteaban indiscriminadamente los derechos civiles y políticos a regímenes democráticos que garantizan condiciones mínimas de libertad e igualdad a sus ciudadanos, el tránsito de sociedades articuladas por el Estado-fuerza a sociedades secularizadas donde más que el orden predomina el conflicto, el tránsito de modelos y patrones de conducta patrimonialistas y paternalistas fuertemente arraigados a otros donde los ciudadanos no tenemos más remedio que valernos por nosotros mismos.

En ese mismo tenor, así como debe constatarse la existencia de una nueva y prometedora cuestión social, también debe advertirse que la profunda crisis política, económica y social de nuestros países se ha traducido de igual forma en una profunda crisis moral. En efecto, el malestar, la pobreza y la ignorancia van de la mano de una creciente violencia y descomposición social. Por eso, hay poco espacio para el optimismo en América Latina. Y sin embargo, pensar la democracia como forma de vida y a la política, o sea al espacio público, como el lugar decisivo de la existencia humana, no deja de tener un ingrediente optimista. En efecto, aunque no tengo ningún argumento para demostrarlo, estoy convencido que las sociedades que avanzan, que conquistan mayores y mejores márgenes de democracia y libertad, dificilmente pueden preferir algo que las haga retroceder, algo que las perjudique; las sociedades que hicieron valer en algún momento su deseo de ser libres, difícilmente regresarán - no al menos voluntariamente - a la servidumbre del pasado autoritario. Es por eso que sostengo que así como la democracia aspira a cada vez más y mejor democracia, también las sociedades libres aspiran a cada vez más y mejor libertad. Con todo, tengo claro que hablar de la democracia desde lo social supone reconocer la total indeterminación de lo político.

Cualquiera que sea el derrotero de nuestros países en el futuro inmediato, una cosa es cierta: nada preexiste al momento del encuentro o la interacción de los ciudadanos; es aquí, en el espacio público, donde se definen y afirman los valores (y los contenidos de esos valores) que como tales han de articular a la sociedad. Es más, reconocer la centralidad del espacio público para la democracia es reconocer que todo, absolutamente todo, es o puede ser politizable, a condición de que sea debatible, que se convierta en un asunto de deliberación pública e interés social.

Así como no puede entenderse la persistencia de nuestras democracias sin la concurrencia de la sociedad civil, los escasos avances alcanzados hasta ahora - ya sea la ampliación de derechos a sectores antes discriminados 
o la extensión de derechos civiles y políticos a grupos sociales minoritarios o cualquier otro logro-, todos sin excepción, son conquistas sociales que ningún político puede abrogarse como éxitos propios sin faltar a la verdad; son conquistas sociales porque primero fue la idea y luego la acción, y la idea no es una ocurrencia de un tecnócrata sino una necesidad sentida de la sociedad. En suma, el Estado de derecho o incluso una Constitución sólo pueden perfeccionarse o reformarse en tensión creativa con la sociedad, con sus necesidades, anhelos y sueños.

En otras palabras, si la democracia institucional se mantiene en la región y además muestra algunos avances aunque lentos es debido primordialmente a la intervención de la sociedad civil más que a las virtudes y el compromiso social de los políticos profesionales, y si la democracia se mantiene como está, o sea atravesada por enormes problemas e inconsistencias, es debido primordialmente a la incompetencia, las ambiciones desmedidas o simplemente el desinterés de la clase política en su conjunto más que a la ignorancia, la desinformación o la apatía de la sociedad. En efecto, no conozco todavía a ningún ciudadano que no aspire a tener mejores gobernantes, mejores partidos, mejores representantes, mejores leyes, mejores garantías y mejores libertades, pero sí conozco a muchos políticos profesionales que sólo aspiran a ascender en sus carreras políticas, con el respaldo social o sin él.

Si esto es así, habría que poner en tela de juicio aquellas posiciones que miran con desdén el aporte ciudadano a la democracia en América Latina, y que se refieren a los ciudadanos de nuestra región como "ciudadanos de baja intensidad" o "ciudadanos precarios". ${ }^{9}$ En contra de este tipo de posiciones, considero que no es poca cosa para cualquier sociedad tener que cargar sobre sus espaldas con todo el peso que significa mantener democracias tan endebles y frágiles como las latinoamericanas (sometidas a tantos embates que la amenazan permanentemente, empezando por la ineficacia y el desinterés de las elites políticas). Es más, en contraste con lo que ocurre en democracias consolidadas, donde las instituciones y las prácticas democráticas, por así decirlo, caminan solas, en democracias no consolidadas, el papel de la ciudadanía es por necesidad más activo y decisivo, pues si los individuos en estas realidades insuficientemente democráticas flaquean y no se hacen cargo de dichas inconsistencias lo más probable es que se retrocedería a estadios predemocráticos a los que la mayoría no quisiera regresar bajo ninguna circunstancia.

Sin embargo, como hemos visto aquí, vivir en democracia en América Latina es vivir al borde, en el filo frágil y breve de un vaso que corta y que

\footnotetext{
${ }^{8}$ O’Donnell, G., "Delegative Democracy", Fournal of Democracy, vol. 5, núm. 1, pp. 13-23.

${ }^{9}$ Durand Ponte, V. M., Desigualdad social y ciudadanía precaria. ¿Estado de excepción permanente?, México, Siglo XXI Editores-UnAM, 2010.
} 
en cualquier momento puede quebrarse. Los peligros que la amenazan son tantos que apostar por su consolidación resulta en ocasiones ingenuo. Ahí están, por ejemplo, los peligros de la (re)militarización, del predominio de los poderes fácticos, de la corrupción desmedida, del populismo y la personificación de la política, de la desigualdad social y de la informalización de la política. Pero vivir en democracia en América Latina, además del desencanto y la frustración que ha supuesto para muchos, es conquista y afirmación permanente de ciudadanía, es decir de hombres y mujeres libres que nos sabemos cada vez más artífices de nuestro destino, que intuimos que cualquier decisión que no haya emanado de la propia sociedad, de sus necesidades y expectativas, de sus valores y posicionamientos, será ilegítima e impopular. Vivir en democracia es en suma, hacer democracia, inventarla todos los días en los espacios públicos, en el encuentro cotidiano con los otros; es corroborar que somos nosotros, los ciudadanos, los verdaderos sujetos de la política, a condición de participar en los asuntos públicos, o sea de debatir y opinar; es un reclamo permanente de ciudadanía contra todos aquellos que nos la expropian arbitrariamente.

Visto desde Europa o Estados Unidos, que desde hacía mucho tiempo no resentían los embates de una crisis económica tan compleja como la actual, es hasta cierto punto lógico que la mayoría de los cuestionamientos se dirijan hacia la propia democracia, o sea hacia los gobernantes electos democráticamente, incapaces todos de enfrentar con un margen aceptable de eficacia las arremetidas de la crisis, independientemente de su origen partidista o ideológico. No sorprende, por ejemplo, que varios intelectuales europeos y estadounidenses propongan hoy, después de décadas de políticas neoliberales, un retorno a las políticas bienestaristas de antaño o que se introduzcan auténticas e innovadoras fórmulas redistributivas para compensar la creciente inequidad y malestar social que está dejando la crisis económica en todas partes y que de paso vulnera la legitimidad de la democracia. ${ }^{10}$ Tampoco sorprende que otros autores empiecen a considerar a la democracia como una ficción que ha dejado de ser confortable, pues si antes prevalecía entre los ciudadanos en las democracias avanzadas una confianza básica en las instituciones que desalentaba su participación, hoy se ha incrementado la desconfianza, aunque eso no significa necesariamente que ahora los ciudadanos deseen involucrarse políticamente más que antes. ${ }^{11} \mathrm{Y}$, finalmente, tampoco desconcierta que hoy muchos piensen que la democracia

\footnotetext{
${ }^{10}$ Véase, por ejemplo, Roberts, A. The Logic of Discipline. Global Capitalism and the Arquitecture of Government, Oxford, Oxford University Press, 2013; Beck U., German Europe, Londres, Polity Press, 2013.

${ }^{11}$ Véase T. Meaney y Y. Mounk, op. cit., nota 5.
} 
únicamente es una forma de gobierno que permite que la gente tome malas decisiones sin destruir el orden político en su conjunto, o sea que es una ilusión pensar que la democracia garantiza, a diferencia de otros regímenes, mejores resultados políticos o económicos. ${ }^{12}$

Pero desde América Latina, donde más que un accidente la crisis económica y social es un modus vivendi, las cosas se ven relativamente distintas que en Europa y Estados Unidos. La democracia puede ser aquí un auténtico desastre (tentaciones autoritarias, ingobernabilidad, corrupción, ilegalidad, opacidad, abusos de autoridad, impunidad, inseguridad, ineficacia gubernamental, etcétera), pero siempre será preferible a los excesos y atrocidades autoritarios del pasado no muy remoto. Los ciudadanos en América Latina hemos aprendido mejor que en otros países que cuentan con democracias más estables que lo que no hagamos nosotros para capotear cotidianamente la crisis económica y la inequidad social no lo hará nadie, que si no somos nosotros los que hacemos valer nuestros derechos frente a la insensibilidad y la sordina de las autoridades e instituciones políticas y jurídicas seremos condenados al ostracismo, que si no tendemos puentes entre nosotros para hacernos escuchar nadie nos tomara en cuenta... En una palabra, hemos aprendido a punta de infortunios, que siempre será preferible vivir en condiciones imperfectas de libertad e igualdad como las que hoy existen en la mayoría de nuestros países que en condiciones en las que simplemente estén ausentes las garantías individuales más elementales. Esta certeza nos permite afirmarnos como ciudadanos y aferrarnos a la democracia aunque por momentos parezca que todo está por hacerse.

Pero incluso un país tan poderoso como Estados Unidos, al que hoy se le achacan nuevas y terribles tribulaciones políticas, es un ejemplo insuperable para documentar un cierto optimismo hacia la democracia, a condición de entenderla no sólo como una forma de gobierno sino sobre todo como una forma de vida o de sociedad. En efecto, después de décadas en las que parecía que con la democracia representativa no pasaba nada nuevo, pues prevalecía intacta una confianza básica en las instituciones y en la grandeza de la nación, en menos de una década muchas de estas convicciones se tambalearon aparatosamente y en su lugar aparecieron nuevas esperanzas y lecciones. Después del trauma provocado por los actos terroristas del 11 de septiembre de 2001, el pueblo estadounidense decidió reinventarse, dejar en el pasado dos siglos de discriminaciones y resabios raciales y étnicos para darle un nuevo contenido a los valores de la igualdad, la tolerancia y el reconocimiento. Precisamente por ello, la elección de Barack Obama el 4 de noviembre de 2008, como primer presidente negro en la historia de América, es mucho más que un hecho circunstancial, es la constatación material de un cambio de mentalida-

${ }^{12}$ Idem. 
des inusitado. Que la oferta política de Obama haya movido las fibras más sensibles de un pueblo a la deriva, urgido de nuevas esperanzas y certezas, es incuestionable, pero el dato realmente relevante es que por primera vez no importaron para la mayoría de los estadounidenses, empezando por los anglosajones, consideraciones raciales o religiosas o de cualquier otro tipo. He ahí, precisamente, la novedad de la democracia en América en este principio de siglo, una novedad que reconcilia a los estadounidenses con la política y con la democracia, y que marca el único derrotero posible para el resto del planeta. La lección es clara: sin tolerancia y pleno reconocimiento de los derechos de todos sin distinción, la democracia es tan sólo una quimera. Si hace apenas setenta años no se podía hablar de democracia plena en la medida que a la mitad de la población le eran negados sus derechos políticos más elementales, me refiero a las mujeres, ahora sólo se podrá hablar de democracia plena cuando se hayan abandonado por completo los resabios raciales, religiosos o de cualquier otro tipo. Una lección seguramente difícil de aprender para las democracias europeas, tan acomplejadas como prejuiciosas, pero ineludible para las nuevas generaciones en todas partes. ${ }^{13}$

\section{4}

Si la democracia ha de ser concebida, como proponía Tocqueville, como algo más que una forma de gobierno, o sea como una forma de sociedad, de vida social, entonces los cambios en su seno, los más profundos y trascendentes, son los que acontecen en las percepciones y los imaginarios colectivos de los ciudadanos, o sea en sus valores. Sólo en la democracia, es decir, en condiciones mínimas de libertad e igualdad, toca a los ciudadanos instituir desde el debate público y el diálogo permanente entre pares, los valores (y los contenidos de esos valores) que han de regir el todo social, incluida no sólo la ciudadanía sino sobre todo la autoridad. Esta perspectiva no sólo le hace justicia a la idea de soberanía popular inherente a la democracia sino que permite aprehender de manera más realista que otros enfoques, como los meramente institucionalistas, las verdaderas transformaciones que acontecen en las democracias modernas. Cambios en el sistema de partidos o en la composición de los poderes o incluso reformas constitucionales más o menos amplias son cambios morfológicos inherentes a todo régimen democrático, pero los verdaderos cambios de fondo son siempre los cambios culturales, los que tienen lugar en las mentalidades de los pueblos, en sus percepciones y anhelos. Y es precisamente aquí donde podemos reconocer lo verdaderamente "nuevo" de la democracia en este siglo XxI.

${ }^{13}$ Más sobre este tema puede encontrarse en Cansino, C., La nueva..., op. cit., nota 7. 
En suma, Bobbio tenía razón. La democracia que él anticipó hace treinta años no podía estar más amenazada y vulnerada que como lo está ahora en todas partes. En realidad, hay pocas razones para ser optimistas. A las viejas promesas incumplidas de la democracia que muy bien ensayó Bobbio hay que sumar nuevas y cada vez más terribles. Sin embargo, las democracias de hoy cuentan con un activo que mal haríamos en desdeñar: una ciudadanía cada vez más informada, crítica y participativa que se percibe cada vez más como la protagonista de su tiempo y su destino. Sobra decir que si la democracia ha de ser todavía una promesa realizable para el futuro depende solamente de nosotros.

\section{POST SCRIPTUM}

Han pasado 30 años de la publicación de El futuro de la democracia, y 10 del fallecimiento de su autor. Su legado intelectual es apreciado por todos. Se recordará sobre todo por su integridad e independencia intelectuales, por su disposición para dialogar con el adversario, y por la claridad de su pensamiento y pulcra escritura. Un faro, como dicen los italianos, que iluminó el debate intelectual en su país por más de medio siglo. Filósofo del derecho, historiador de las ideas, filósofo político, politólogo, qué más da. El conjunto de su obra es la de un pensador comprometido con su tiempo. De ahí sus temas recurrentes: la cultura, los intelectuales, el carácter conflictivo de la política, la democracia, las ideologías, la guerra y la paz, las doctrinas políticas. Toca a cada quien, entre sus lectores y discípulos, situar sus afinidades y discrepancias con respecto a la obra del filósofo italiano. En lo personal, me quedo con el Bobbio historiador de las ideas, el Bobbio lector apasionado de los clásicos. Pero reconozco que su contribución a la teoría democrática es inconmensurable.

En su libro El futuro de la democracia, Bobbio no sólo advirtió con maestría las contradicciones inherentes a las democracias modernas, sus características y desafios, sino que se adscribió a sus preceptos a pesar de las promesas que en su nombre tantas veces se hicieron y nunca se cumplieron. Al reconocer los valores de la democracia, promovió también su lealtad con ella, su confianza en las instituciones y los ciudadanos.

Y a la hora de los homenajes, pensando desde nuestra propia circunstancia, habrá que reconocer ante todo la enorme influencia que el pensamiento de Bobbio ejerció en Iberoamérica, en un momento en que las disputas ideológicas todo lo enturbiaban y enlodaban, en una época en que la democracia resurgía después de trágicos intervalos dictatoriales, pero sin muchos referentes para reivindicarla más allá del repudio a los regímenes militares. Por ahí quisiera comenzar.

$\mathrm{Al}$ igual que muchos otros jóvenes universitarios en el México de los años ochenta, me enganché con la filosofía política y con la teoría demo- 
crática gracias a la obra de Bobbio, que apenas comenzaba a traducirse al castellano por esos años. No creo exagerar al decir que si México es hoy un país democrático o al menos más democrático que entonces se debe en alguna medida a la seducción que este autor tuvo en esa generación y en otras posteriores. Y es que Bobbio seducía por su claridad, por su didáctica, por su contundencia. En un país como el México posrevolucionario, donde la democracia era pura demagogia, una palabra prostituida por los políticos de turno, empleada para adornar discursos vacíos y pedestres, Bobbio le restituía dignidad con sólo definirla, pues la despojaba de toda la bazofia con la que solía asociarse. El hecho de poder reconocer con claridad y sencillez, leyendo a Bobbio, lo que la democracia es y no es, constituía por sí sólo un acto rebelde, en el contexto de un régimen donde la ambigüedad y la labia eran consustanciales, un régimen autoritario en los hechos aunque democrático en los discursos.

La obra de Bobbio sobre la democracia llegó a México y a Iberoamérica en el momento justo, en el momento en que las dictaduras militares o disfrazadas hacían agua por doquier y la democracia se asomaba titubeante. Pero sobre ésta había más confusión que claridad, más dudas que certezas. Por una parte, las experiencias democráticas previas a la era autoritaria fueron contradictorias y deficientes. En su nombre, salvo muy escasas excepciones, se erigieron sistemas políticos corruptos y discrecionales, verdaderos templos a la impunidad y la arbitrariedad, oligarquías perennes, populismos demagógicos, corporativismos verticales, etcétera. Por otra parte, se manoseó tanto la democracia con fines políticos y de legitimación, que terminó vaciándose de significados fuertes. La democracia era todo y nada a la vez. Por ello, nunca fue un referente simbólico medianamente compartido y asumido. Finalmente, para completar el cuadro, la reyerta ideológica propia de los años sesenta, setenta y ochenta vio en la democracia la manzana de la discordia, y con ello aumentó la confusión. Para unos, la democracia era "burguesa", un instrumento al servicio de una clase para asegurar su permanencia, por lo que reivindicaban en su lugar la "democracia popular". Para otros, la democracia era liberal o simplemente no era democracia.

Y precisamente aquí entra Bobbio. Es indudable que su obra en general y sus reflexiones sobre la democracia en particular prendieron de inmediato en toda la región. ¿Por qué? Porque hasta entonces nadie había sido más claro, más preciso y contundente que él. Su discurso nos ayudó en su momento a reconocer sin artificios verbales los valores de la democracia y a vislumbrar un horizonte por el que era posible y deseable transitar. Después de décadas de retóricas democráticas, disputas ideológicas y promesas quiméricas de emancipación, Bobbio fue para nosotros una bocanada de aire fresco. Que la obra de Bobbio no haya tenido el mismo impacto en otras latitudes y sobre todo en países con tradiciones democráticas más consolidadas se explica en buena 
medida porque en los nuestros la democracia estaba toda por construirse, empezando por definirla conceptualmente para poder entenderla y valorarla.

Quizá ni el propio Bobbio sospechó que sus reflexiones sobre la democracia tendrían tanto impacto en Iberoamérica. Él pensaba sobre todo en la circunstancia italiana, en la continua crisis política de su país. Pero a diferencia de muchos escépticos, Bobbio siempre creyó que la democracia no sólo era posible en sociedades desarrolladas, sino que terminaría por extenderse a otros países. La ola democratizadora de los años ochenta y noventa terminó dándole la razón. Ciertamente, desde que Bobbio aventuraba sus tesis sobre el futuro de la democracia, muchas cosas han cambiado. De la sociedad industrial y el Estado de bienestar pasamos a la sociedad sin trabajo, dominada por la revolución de la tecnología y la informática y por el excesivo poder de las fuerzas económicas que disfrutan de la dimensión global de los mercados. La derrota del socialismo real y la presión de la globalización pusieron en crisis a las instituciones representativas. La democracia parlamentaria cede su lugar a la "videocracia", la lógica de la representación es subrogada por la lógica mercantil de la propaganda política y la "sondeocracia", el capitalismo hegemonizado por una sola potencia ha generado nuevos enconos y asonadas militaristas, cuestiones todas que Bobbio no anticipó, pero que fue incorporando sucesivamente a la reflexión. Con todo, su contribución al debate político y al avance democrático en un tiempo crucial para Iberoamérica ahí queda como la herencia intelectual de un pensador comprometido con su tiempo y sus ideales. 
